\title{
Cholestasis: The ABCs of cellular mechanisms for impaired bile secretion - Transporters and genes
}

\author{
Eldon A Shaffer MD FRCPC
}

\begin{abstract}
EA Shaffer. Cholestasis: The ABCs of cellular mechanisms for impaired bile secretion - Transporters and genes. Can J Gastroenterol 2002;16(6):380-389.
\end{abstract}

The transport of bile salts, organic anions and cations, bilirubin and other substances from the portal blood into the biliary system is accomplished through the action of an array of transporter proteins in the hepatocyte. Transporters on the basolateral membrane, which faces the space of Disse, are responsible for the uptake of bile salts and organic anions. Once translocated through the hepatocyte to the canalicular membrane, other ATP pumps provide the energy to export bile salts, phospholipids and organic ions into the bile. Canalicular transport is rate limiting. Defects in specific canalicular transporters are responsible for many of the intrahepatic cholestatic syndromes that occur in children and adults. Moreover, cholestasis provokes changes in several transport mechanisms, many of which appear to be compensatory and serve to protect the liver from the toxic effects of accumulated materials. The identification and characterization of the major transporters responsible for bile formation have yielded a more precise classification of the cholestatic syndromes of infancy and childhood, and are unlocking the molecular mechanism of acquired cholestasis in adults. This review identifies the basic physiology of bile production and the actions of the key transporters, indicates the clinical relevance and possible treatments of transport disorders, and provides an illustrative case.

Key Words: Basolateral membrane transport; Bile; Bile flow; Bile salt; Canalicular transport; Cholestasis; Cholesterol gallstones; MDR3 deficiency; Multidrug resistance protein; Progressive familial intrahepatic cholestasis

\section{Cholestase : mécanismes cellulaires de base et troubles de la sécrétion biliaire - les transporteurs et les gènes}

RÉSUMÉ : Le transport des sels biliaires, des anions et des cations organiques, de la bilirubine et d'autres substances depuis le système porte vers le système biliaire se fait par l'intermédiaire d'une foule de transporteurs protéiniques dans les hépatocytes. Les transporteurs qui se trouvent sur la membrane basolatérale, faisant face à l'espace de Disse, se chargent de l'absorption des sels biliaires et des anions organiques. Une fois leur passage terminé dans les hépatocytes vers la membrane canaliculaire, d'autres pompes à ATP fournissent l'énergie nécessaire pour exporter les sels biliaires, les phospholipides et les ions organiques dans la bile. Certains transporteurs canaliculaires défectueux sont alors cause de nombreux syndromes cholestatiques intrahépatiques, observés chez les enfants et les adultes. De plus, la cholestase elle-même altère plusieurs mécanismes de transport; il s'agit là probablement d'un comportement compensateur visant à protéger le foie des effets toxiques de l'accumulation des substances. L'identification et la caractérisation des principaux transporteurs responsables de la formation de la bile ont permis une classification plus précise des syndromes cholestatiques chez les nourrissons et les enfants ainsi que la découverte des mécanismes moléculaires de la cholestase acquise chez les adultes. Le présent article passe en revue la physiologie de base des mécanismes producteurs de bile et les actions des principaux transporteurs, fait état de la pertinence clinique et des traitements possibles des troubles de transport et illustre les explications d'un exposé de cas.

Division of Gastroenterology, Health Science Centre, University of Calgary, Calgary, Alberta

Correspondence and reprints: Dr EA Shaffer, Division of Gastroenterology, Health Science Centre, University of Calgary, 3330 Hospital Dr NW,

Calgary, Alberta T2N 4N1. Telephone 403-210-9363, fax 403-210-9340,e-mail shaffer@ucalgary.ca

Received for publication March 12, 2002. Accepted March 12, 2002 
$\mathrm{T}$ he physiologist regards 'cholestasis' as a failure of bile secretion. Impairment can occur at any site along the hepatobiliary system. A functional disorder of hepatocytes in which bile is formed is termed 'hepatocellular cholestasis', whereas an obstruction of the bile ductules or ducts is 'ductular' or 'ductal' cholestasis, respectively. Therefore, for the clinician, cholestasis represents either a disorder of hepatocyte function or an obstruction of the duct system. The latter may be congenital, such as in biliary atresia, or acquired, as with stones or a tumour. The common manifestations of cholestasis - pruritus, jaundice and fat malabsorption - are not generally diagnostic; neither are the common tests of liver biochemistry. Visualization of the biliary system by ultrasonography and/or a cholangiographic technique is required to rule out a readily correctable obstructing process (ie, 'surgical jaundice' due to extrahepatic biliary obstruction) (1).

Bile secretion depends on a series of transport systems embedded in the membranes of liver cells and bile duct epithelial cells (cholangiocytes). The recent identification and characterization of the major transporters responsible for bile formation have yielded a more precise classification of the cholestatic syndromes of infancy and childhood, and have provided insight about the molecular mechanisms of acquired cholestasis in adults.

This review puts into perspective the molecular basis for hepatocellular transport and clarifies the transport dysfunctions that cause cholestasis in infancy and childhood, thus simplifying the previously complex classification of cholestatic syndromes. It also delineates the biochemical responses to acquired cholestasis, many of which are compensatory adaptations.

\section{CASE PRESENTATION}

An infant girl became jaundiced at four weeks of age. Her delivery was somewhat premature, at 37 weeks, but was otherwise uneventful. Her parents were not consanguineous. The mother had experienced pruritus without jaundice during the last trimester and had previously required surgery for symptomatic cholelithiasis. The infant appeared normal except for icterus. Laboratory investigations showed a fourfold elevation of the serum (conjugated) bilirubin level and a high gamma-glutamyl transpeptidase ( $\gamma \mathrm{GT}$ ) level, but results of a metabolic evaluation were normal. The abdominal ultrasound was remarkable only for a small, contracted gallbladder. The hepatobiliary scan (cholescintigraphy) demonstrated prompt uptake of the radiopharmaceutical but no excretion into the bile ducts. Subsequent liver biopsy showed a mild, nonsuppurative cholangitis with portal inflammation and early ductal proliferation. The conjugated hyperbilirubinemia persisted through infancy, requiring exploratory laparotomy that revealed patent extrahepatic bile ducts. Pruritus became a problem at age two years. A trial of ursodeoxycholic acid produced no improvement, and repeat liver biopsy showed cirrhosis. At three years of age, she developed portal hypertension, with a variceal hemorrhage and liver failure, and became a candidate for liver transplantation.

\section{THE BASIS FOR BILE FORMATION}

The human liver secretes over $500 \mathrm{~mL}$ of bile each day. This product both rids the body of potentially noxious products and provides the biological detergents necessary for fat solubilization and digestion. The membrane surface of the hepatocyte is functionally divided into the following two regions:

- The basolateral (sinusoidal) region comprises approximately $85 \%$ of the total surface area and consists of a basal portion, facing the blood-filled sinusoidal space, plus the lateral surfaces next to the neighbouring hepatocytes.

- The smaller apical (canalicular) region, which occupies approximately 15\% of the surface area, lines the groove or cleft between adjacent liver cells.

Bile canaliculi are each formed from two of the half-tubules that are carved out of the apical surfaces of adjacent hepatocytes. They are the smallest $(0.75 \mu \mathrm{m}$ in diameter $)$ and most proximal branches of the biliary tree (2). The canaliculus is the site at which the active transport of bile salts and other organic solutes initiates bile formation. A complex cytoskeleton, which includes circumferential actin filaments, supports the canaliculus and exhibits spontaneous contractions that promote distal movement of bile. This contractile mechanism is altered in cholestasis (3).

Junctional complexes (tight junctions) separate the canaliculus from the basolateral hepatocyte membrane, thus preventing a free exchange of ions, organic solutes and water with the extracellular space (space of Disse) (Figure 1). Some bile canaliculi, however, reside in close proximity $(0.1 \mu \mathrm{m})$ to the space of Disse, providing a potential route for the regurgitation of bile into sinusoidal blood in patients with cholestasis.

This anatomical arrangement causes the hepatocyte to be polarized, in that it facilitates the vectoral transport of solutes from blood to bile. Uptake transporters exist on the basolateral surface, next to the portal blood vessels, while export transporters reside on the canalicular surface, where bile forms. Solutes must either cross the hepatocyte (transcellular pathway) or move through the junctional complexes between the cells (paracellular pathway) to reach the canaliculus (4).

Bile salts, bilirubin and most organic solutes follow the transcellular route. Their concentration in bile is 100 -fold that in serum. Such active transport requires energy, which is generated by ATP hydrolysis and involves coupling of solute transport to the movement of other ions (secondary active transport). The transport of bile salts and their counterion, sodium, creates an osmotic gradient across the hepatocyte. Once in the canalicular lumen, bile salts, reduced glutathione (GSH) and other negatively charged organic anions cannot diffuse back across the junctional complexes or into the liver cell. Water and some electrolytes (through solvent drag) then diffuse down this osmotic gradient using the paracellular route. Thus, active transport systems 


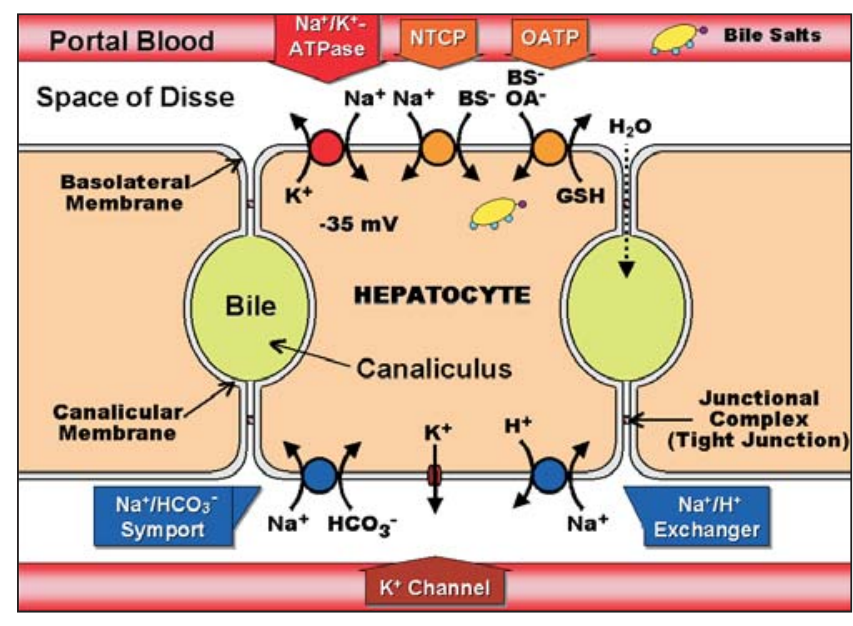

Figure 1) Basolateral membrane transport systems. Transporters are represented as spheres with arrows showing the direction of transport. The sodium pump ( $\mathrm{Na}^{+} / \mathrm{K}^{+}$-ATPase) provides the inwardly directed sodium gradient to secondarily drive the sodium-dependent sodium-taurocholate cotransport polypeptide (NTCP), the major means of bile salt $\left(B S^{-}\right)$uptake. The potassium channel creates the necessary membrane potential $(-35 \mathrm{mV})$. The organic anion transporting protein (OATP) takes up $\mathrm{BS}^{-}$, independent of sodium and organic anions $\left(\mathrm{OA}^{-}\right)$while exporting glutathione (GSH) for latter systemic use. The basolateral membrane also contains a sodium-hydrogen $\left(\mathrm{Na}^{+} / \mathrm{H}^{+}\right)$exchanger that extrudes protons and, therefore, maintains the intracellular $\mathrm{pH}\left(\mathrm{pH}_{i}\right)$. A sodium-bicarbonate symport $\left(\mathrm{Na}^{+} / \mathrm{HCO}_{3}{ }^{-}\right)$takes up these two ions, allowing bicarbonate entry

located at the basolateral and canalicular membranes produce osmotic gradients along which water and electrolytes passively flow. The resultant canalicular bile is nearly isotonic with plasma (5).

Canalicular bile formation consists of two components: the active secretion of bile salts (bile salt-dependent bile flow), which represents the major portion, and the transport of other organic solutes such as GSH plus the canalicular secretion of bicarbonate, without the involvement of bile salts (bile salt-independent bile flow) (6,7). A third component (ductular secretion) comes from the bile channels (bile ductules and ducts) and is largely regulated by hormones such as secretin and neuropeptides (8). Finally, the gallbladder concentrates bile five- to 10 -fold.

Hepatocyte membranes contain proteins that function as pumps and transporters to expedite vectoral movement of solutes (including organic bile solutes such as bile salts and bilirubin, and electrolytes such as sodium) from plasma to bile across the hepatocyte. They establish the osmotic gradients necessary for bile flow between hepatocytes. These transporters are strictly located on either the basolateral or the canalicular membrane. The overall driving force for bile formation is bile salt secretion.

Bile salts are the most abundant organic solutes in bile. About $30 \mathrm{~g}(50 \mathrm{mmol})$ of bile salts are secreted from the liver each day. Their active reabsorption takes place in the terminal ileum. Bile salts then return via the portal vein to the liver, where they are efficiently taken up (more than $95 \%$ in one pass) and secreted once again (9). The capillary structure of the hepatic sinusoids, through which portal blood flows, facilitates this uptake. The endothelium lining the sinusoids do not possess a basement membrane or smooth muscle, but rather have many pores that are arranged as sieve plates. This allows plasma solutes a ready egress to the space of Disse and, hence, the sinusoidal surface of hepatocytes. Inflammation, especially in the setting of systemic infection, induces sinusoidal changes that interfere with the uptake of bile salts and thus cause cholestasis. Reduced perfusion of the liver, as in severe heart failure, also impairs uptake.

\section{BASOLATERAL MEMBRANE TRANSPORT}

Mechanisms whereby bile salts are extracted from the portal blood are illustrated in Figure 1. The sodium pump $\left(\mathrm{Na}^{+} / \mathrm{K}^{+}\right.$-ATPase $)$provides the energy that maintains the ion gradient across the basolateral plasma membrane. It expels three sodium ions for every two potassium ions that move into the cell. Sodium thus predominates outside the cell, whereas the converse applies to potassium. This concentration gradient, assisted by the potassium channel, generates an intracellular negative potential of about $-35 \mathrm{mV}$ (4). These chemical gradients and electrical potentials maintain the intracellular homeostasis of ion concentrations, $\mathrm{pH}$ and volume. They drive proton extrusion via the sodium-hydrogen exchanger, and promote bicarbonate entry via a sodium-bicarbonate symport. (An 'exchanger' moves one ion out and another in, in this case proton for sodium; whereas a 'symport' promotes unidirectional movement of both sodium and bicarbonate ions into the cell.) By generating these transmembrane sodium and electrical gradients, the sodium pump indirectly promotes the uptake of conjugated bile salts (eg, with taurocholate).

The sodium-taurocholate cotransporting polypeptide (NTCP) is the symport that brings about the uptake of sodium and taurocholate into the hepatocyte (10). (By convention, abbreviations of protein names are usually designated by capital letters [eg, NTCP] for humans and lower case [eg, Ntcp] for animals. The responsible genes are italicized.) This electrogenic system takes up two sodium ions for every taurocholate anion, and accounts for most of the conjugated bile salts that are extracted from the portal blood via the space of Disse. Conversely, sodium-independent systems transport some conjugated and unconjugated bile salts, in addition to a large number of organic anions, including hormones (such as estrogens), inflammatory mediators and various xenobiotics, but not unconjugated bilirubin $(11,12)$. This family of transporters with wide substrate preferences is collectively referred to as organic anion transporting polypeptides (OATPs) (13). Organic anion uptake seems to involve anion exchangers. For example, one such protein exchanges organic anions with GSH, which accounts for the efflux of the latter into the space of Disse. Therefore, NTCP and OATPs are responsible for the extraction of bile salts from the portal venous circulation. 


\section{INTRACELLULAR TRANSPORT}

Bile salts diffuse across the hepatocyte to the canalicular membrane, likely in complexes bound to one or more carrier proteins. These proteins, including 3alpha-hydroxysteroid dehydrogenase and GSH, decrease the potential toxicity of the bile salts (14).

\section{CANALICULAR SECRETION}

The canalicular secretion of bile salts is the rate-limiting step in bile formation (Figure 2). Two transport systems are responsible. The major one consists of 'export' pumps that require energy derived from the hydrolysis of ATP. This active transport system is part of the ATP-binding cassette (ABC) superfamily of transport proteins (15-17). Canalicular transport is affected by alterations in gene expression, degradation of transporter proteins and, on a short term basis, substrate availability. The physiological need to secrete bile salts thus regulates the amount of the responsible $A B C$ transporters that are made in the Golgi apparatus and moved to the canalicular membrane $(2,16,17)$. Conversely, transporter deficiency or malfunction impairs bile secretion. The other transport system is ATP-independent, consists of an electrogenic system that is energized by the membrane potential $(4,18)$ and appears to be localized to a subcanalicular microsomal compartment (19). These two types of systems are discussed in further detail below.

\section{ATP-dependent transport}

The important ATP-dependent transport systems in the canalicular membrane are members of two subclasses of the ABC superfamily: the P-glycoprotein (Pgp) subfamily (also termed the $\mathrm{ABC}$ subfamily $\mathrm{B}$ ) and the multidrug resistanceassociated protein (MRP) subfamily (the $\mathrm{ABC}$ subfamily $\mathrm{C}$ ).

Pgps (ABC subfamily B) are expressed in the apical domains of cells with excretory function. They were initially isolated from cells that were multidrug resistant (MDR). Hence, these transport proteins are termed 'MDR' in humans. Subsequent studies found that Pgps were also expressed in normal tissues (ie, not associated with drug resistance). At least four Pgp transporters are located in the canalicular membrane, and others are less well defined.

- MDR1 transporters excrete lipophilic cations, including drugs (20). Though normally present in the liver at low levels, MDR1 may serve to protect the hepatocyte from the toxic effects of xenobiotics and ingested toxins by excreting these agents into the bile.

- The phospholipid export pump (MDR3) functions as a 'flipase', in that it translocates (ie, flips) the phospholipid lecithin from the inner to the outer leaflet of the canalicular membrane (21). Bile salts then complete the extraction of lecithin into the canalicular lumen. Within the lumen, lecithin forms mixed micelles with bile salts and cholesterol, in

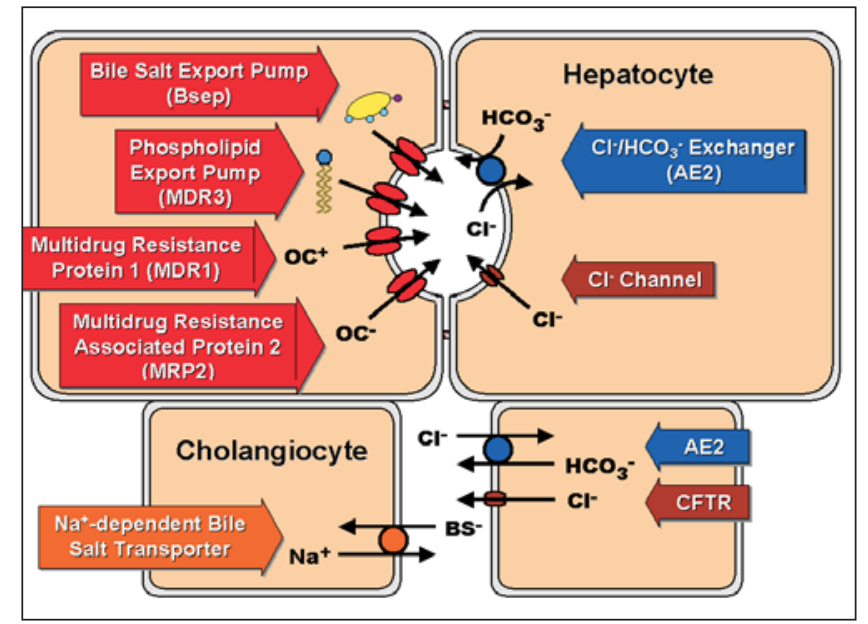

Figure 2) Top Hepatocyte canalicular membrane transport. The ATP-dependent export pumps include: the bile salt export pump; a phospholipid transporter (flipase), called the multidrug resistance P-glycoprotein 3 (MDR3); a related member of the P-glycoprotein family, $\mathrm{MDR} 1$, which excretes lipophilic cations $\left(\mathrm{OC}^{+}\right)$such as drugs; and a conjugate export pump for organic anions $\left(\mathrm{OC}^{-}\right)$such as bilirubin glucuronide, termed the multidrug resistance-associated protein 2 . These are all part of the family of ATP-binding cassette transport proteins. The ATP-independent transport system consists of an anion exchanger $\left(\mathrm{Cl}^{-} / \mathrm{HCO}^{-}\right)$, also termed AE2, plus a chloride channel ( $\mathrm{Cl}^{-}$channel). Bottom Cholangiocyte apical membrane transport. The bile duct transporters include the AE2 (chloride/bicarbonate) exchanger, the cystic fibrosis transmembrane regulator (CFTR) for chloride and the ileal sodium-dependent bile salt transporter

addition to creating unilamellar vesicles with cholesterol. MDR3-dependent phospholipid transport into bile, therefore, solubilizes cholesterol; bile salts also incorporate lecithin, forming mixed micelles that help to solubilize cholesterol. The latter arrangement with lecithin defends canalicular and bile duct membranes against the detergent action of bile salts. Mutations in the responsible human gene, MDR3, are associated with cholestasis and cholesterol gallstone formation (22).

- The bile salt export pump (BSEP), initially cloned as a homologous or 'sister' gene to Pgp (and therefore originally called Spgp), is responsible for bile salt secretion into the canaliculus (13). Mutations in the human BSEP gene result in markedly decreased bile secretion and a hereditary form of intrahepatic cholestasis (23).

- Familial intrahepatic cholestasis 1 (FIC1), one of the less well-characterized transporter proteins, is an aminophospholipid translocase. It maintains the phospholipid content of the inner leaflet of the plasma membrane (23). Mutations of the FIC1 gene cause a form of hereditary cholestasis, perhaps demonstrating the importance of the lipid composition of the canalicular membrane for bile salt secretion. 
TABLE 1

Phenotypes of genetic defects in transport systems

\begin{tabular}{|c|c|c|c|}
\hline Transporter & Function & Name of genetic defect & Phenotype \\
\hline \multicolumn{4}{|l|}{ Basolateral membrane } \\
\hline Transporters & & None described & \\
\hline \multicolumn{4}{|l|}{ Canalicular membrane } \\
\hline $\begin{array}{l}\text { Phospholipid transporter } \\
(\text { MDR3)* }\end{array}$ & $\begin{array}{l}\text { Transfers lecithin from inner to } \\
\text { outer leaflet of membrane ('flipase') }\end{array}$ & $\begin{array}{l}\text { PFIC-3 } \\
\text { Spectrum of milder forms } \\
\text { of disease expression }\end{array}$ & $\begin{array}{l}\text { Familial cholestasis with high } \gamma \mathrm{GT} \\
\text { Cholestasis of pregnancy } \\
\text { Cholesterol gallstones }\end{array}$ \\
\hline Bile salt export pump* & $\begin{array}{l}\text { Primary transporter of bile salts } \\
\text { into canalicular lumen }\end{array}$ & PFIC-2 & Familial cholestasis with low $\gamma$ GT \\
\hline $\begin{array}{l}\text { P-aminophospholipid } \\
\text { translocase }(\mathrm{FIC} 1)^{*}\end{array}$ & $\begin{array}{l}\text { Maintains phospholipids } \\
\text { of inner leaflet of membrane }\end{array}$ & $\begin{array}{l}\text { PFIC-1 (Byler disease) } \\
\text { BRIC }\end{array}$ & $\begin{array}{l}\text { Familial cholestasis with low } \gamma \mathrm{GT} \\
\text { Recurrent cholestasis }\end{array}$ \\
\hline $\begin{array}{l}\text { Multidrug resistance- } \\
\text { associated protein } 2^{*}\end{array}$ & $\begin{array}{l}\text { Export pump for organic } \\
\text { anions (eg, bilirubin) }\end{array}$ & Dubin-Johnson syndrome & $\begin{array}{l}\text { Failure to excrete conjugates } \\
\text { of bilirubin (diglucuronide) } \\
\text { and other organic anions }\end{array}$ \\
\hline Chloride channel & Chloride secretion into bile & None described & \\
\hline \multicolumn{4}{|l|}{ Ductular membrane } \\
\hline $\begin{array}{l}\text { Cystic fibrosis } \\
\text { transmembrane } \\
\text { regulator }\end{array}$ & Chloride secretion & Cystic fibrosis & $\begin{array}{l}\text { Cholestasis, bile plugs, bile duct } \\
\text { proliferation, biliary fibrosis, } \\
\text { and cirrhosis }\end{array}$ \\
\hline
\end{tabular}

The MRP family (ABC subfamily $C$ ) consists of at least six members. (Their original symbols, such as MRP1-6, became redesignated as ABCC1-6 [24].) This MRP family of membrane transporters mediates the ATP-dependent excretion into the systemic circulation of a wide range of organic anionic compounds. MRP1 (ABCC1) was the first identified in a cancer cell line that was resistant to multiple drugs - hence its name. MRP3 (ABCC3) functions as an export pump, although it is located on the basolateral membrane. In cases of cholestasis, MRP3 provides an alternative exit for hepatic conjugates into sinusoidal blood.

MRP2 (ABCC2), located in the canalicular membrane, is an export pump for compounds that are conjugated in the liver. It mediates the ATP-dependent excretion of a broad range of organic anions, mostly conjugates with GSH, glucuronide (eg, bilirubin, estrogens and leukotrienes) and sulphates. Because MRP2 functions as a multispecific organic anion transporter, its original name was cMOAT (25). Export of these osmotically active solutes contributes to bile flow, independent of bile salt secretion. Without MRP2, biliary secretion of many lipophilic anionic conjugates is not possible (26). Mutations of the MRCP2 gene likely explain the excretory defect for bilirubin and other anionic conjugates in the Dubin-Johnson syndrome (27). Because MRP2 is not responsible for bile salt transport, its absence in the Dubin-Johnson syndrome affects the excretion of organic anion but not of bile salts; therefore, true cholestasis does not occur.

\section{ATP-independent transport}

The canalicular membrane also contains transport processes that are not energy dependent, and thus do not require ATP. For example, the chloride/bicarbonate anion exchanger (AE2, a member of the AE 1-3 family) secretes bicarbonate and promotes bile flow (28). The chloride channel drives this exchanger but is distinct from the cystic fibrosis transmembrane regulator (CFTR).

\section{Bile duct transporters}

Secretion and absorption also occur in the bile duct system. Cholangiocytes possess both the AE2 chloride/bicarbonate exchanger and the CFTR chloride channel (29). The ileal sodium-dependent bile salt transporter is present on the apical surface of large cholangiocytes (30). It appears to be involved in the reabsorption of bile salts, which then pass via the peribiliary plexus into the portal vein and are again extracted by the liver. This pathway is known as the cholehepatic shunt.

\section{MECHANISMS OF CHOLESTASIS - DEFECTS IN TRANSPORT PROTEINS}

Transport function is dynamically altered when cholestasis arises. Different transporters are variably altered. Some are downregulated to cause or contribute to the cholestasis, whereas others are relatively maintained or even upregulated to limit liver injury. In addition, changes in the level and activity of transporters, due to inherited defects or 
exposure to external factors, cause a variety of phenotypic expressions of cholestasis and liver disease. Because they constitute the rate-limiting step in bile formation, the export pumps in the canalicular membrane are more important to cholestasis than are the basolateral transporters. Current knowledge of the molecular basis for several forms of cholestatic liver disease has come from investigations of transporter gene expression in animal models of cholestasis (both intra- and extrahepatic) and human studies (31-33).

\section{Inherited cholestatic syndromes}

Characterization of hepatic transport proteins has yielded a more precise definition of several pediatric cholestatic syndromes, especially those causing progressive familial intrahepatic cholestasis (PFIC) $(24,32-34)$. According to the original description of Amish families afflicted with Byler disease, cholestasis develops in the neonatal or early childhood period and culminates in death from advanced cirrhosis, often by adolescence. There are four known phenotypes of PFIC, and each is inherited in an autosomal recessive manner. The associated chronic hepatocellular cholestasis lacks an identifiable anatomical cause or previously obvious metabolic cause. Their etiologies have become clearer, as summarized in Table 1 . The specific syndromes can be classified according to the following responsible genetic defects.

- PFIC-1 (Byler disease) arises from a mutation of the FIC1 gene, located on the long arm of chromosome 18 (18q21-22) (35). The resultant failure to express ATP-dependent aminophospholipid transport presumably impedes bile salt transport by altering the lipid composition of the canalicular membrane (23). Despite the presence of cholestasis and elevated alkaline phosphatase and serum bile salt levels, the $\gamma \mathrm{GT}$ level is not increased. The normal (ie, low) $\gamma \mathrm{GT}$ level suggests that bile salt secretion is so severely impaired that it does not reach the canaliculi and, therefore, does not invoke canalicular or cholangiolar damage. Histology confirms the presence of only a bland canalicular cholestasis, without ductal damage. Cholestasis begins early in infancy, and jaundice becomes persistent within one to four years. Cirrhosis and liver failure, sometimes complicated by hepatocellular carcinoma, develop by early adolescence. The presence of the FIC1 protein in the small intestine and pancreas might explain the associated problems of malabsorption and pancreatitis that afflict some patients even after liver transplantation.

PFIC-1 exhibits phenotypic heterogeneity. An onset of illness during early childhood is associated with more severe disease. Mutations in the FIC1 gene, however, can also give rise to less severe disorders, such as benign recurrent intrahepatic cholestasis (BRIC) and other forms of recurrent familial cholestasis $(24,34-36)$. Cholestasis in these milder forms occurs without residual hepatic damage, as in cases of BRIC.

- PFIC-2 frequently results from a mutation of the BSEP (re-designated ABCB11) gene, which is located on chromosome 2q24 (37). The absence of BSEP causes retention of 'toxic' bile salts and produces liver injury, which appears morphologically as giant-cell hepatitis. Because bile salts do not reach the canaliculi or ducts, the $\gamma \mathrm{GT}$ level is normal. Following its onset as neonatal hepatitis, PFIC-2 invariably progresses to terminal liver disease by age two to 10 years (34). Liver transplantation is the only effective treatment.

- PFIC-3 results from a mutation of the MDR3 gene (redesignated ABCB4), which is responsible for expressing the canalicular phospholipid export pump $(22,38)$. Failure to flip the phospholipid lecithin from the inner to the outer leaflet of the canalicular membrane prevents bile salts from extracting this phospholipid into bile. In the near absence of phospholipid, mixed micelles and lipid vesicles cannot form; therefore, bile salts presumably form simple micelles, which subsequently extract other membrane lipids and thus damage cholangioles. The resultant ductular damage includes proliferative and inflammatory changes that are responsible for the characteristic elevation of serum $\gamma \mathrm{GT}$ levels. The low biliary phospholipid content also lessens cholesterol solubility, which predisposes the patient to cholesterol gallstone formation $(38,39)$. This might be the basis for the development of microlithiasis in some individuals $(40,41)$.

Many different mutations of the MDR3 gene (on chromosome 7q21) can occur, leading to a variety of clinical manifestations (42). Mutations that completely abrogate MDR3 function result in the onset of severe cholestasis in infancy, the inability to respond to ursodeoxycholic acid and the development of liver failure before adulthood. At the other end of the spectrum, missense mutations may permit some MDR3 expression and function. The resultant disease is less severe, begins later in life and responds to ursodeoxycholic acid.

- Heterozygous MDR3 mutations allow partial MDR3 activity at the canaliculus. Affected individuals, however, are susceptible to the detrimental influences of such extrinsic factors as female sex hormones, and can develop cholelithiasis and intrahepatic cholestasis of pregnancy. In such cases, an increased functional demand and/or a decline in transporter expression or traffic in the hepatocyte appears to overload the compromised export pathway, resulting in cholestasis $(42,43)$. 
TABLE 2

Effects of acquired cholestasis on transport systems

\begin{tabular}{|c|c|c|c|}
\hline Transporter & Function & Effect of cholestasis & Benefit of change in system \\
\hline \multicolumn{4}{|l|}{ Basolateral membrane } \\
\hline$\left(\mathrm{Na}^{+} / \mathrm{K}^{+}-\mathrm{ATPase}\right)$ & $\begin{array}{l}\text { Creates a favourable } \\
\text { sodium gradient }\end{array}$ & Preserved or increased & Aids in cell survival \\
\hline $\begin{array}{l}\text { Sodium-taurocholate } \\
\text { cotransporter }\end{array}$ & Hepatic uptake of bile salts & Decreased & Prevents further uptake \\
\hline $\begin{array}{l}\text { Organic-ion transporter } \\
\text { polypeptide }\end{array}$ & Uptake of organic anions & Possibly decreased & Prevents further uptake \\
\hline MRP1 and MRP3 & $\begin{array}{l}\text { Export pump for conjugates } \\
\text { in liver }\end{array}$ & Increased & $\begin{array}{l}\text { Removes conjugates, such as } \\
\text { bilirubin and bile salt sulphates }\end{array}$ \\
\hline \multicolumn{4}{|l|}{ Canalicular membrane } \\
\hline MDR1 & $\begin{array}{l}\text { Excretes xenobiotics } \\
\text { and cytotoxins }\end{array}$ & Increased & Removes xenobiotics and toxins \\
\hline BSEP & $\begin{array}{l}\text { Primary transporter of bile } \\
\text { salts into canaliculus }\end{array}$ & Relatively preserved & \\
\hline $\mathrm{Cl}^{-} / \mathrm{HCO}_{3}^{-}$exchanger (AE2) & Bicarbonate secretion & Decreased PBC & \\
\hline \multicolumn{4}{|l|}{ Ductular membrane } \\
\hline $\mathrm{Cl}^{-} / \mathrm{HCO}_{3}^{-}$exchanger (AE2) & Bicarbonate secretion & Decreased PBC & \\
\hline $\begin{array}{l}\text { Sodium-dependent } \\
\text { bile salt transporter }\end{array}$ & Cholehepatic shunt & $\begin{array}{l}\text { Increased with ductal } \\
\text { proliferation }\end{array}$ & Enhances bile salt return \\
\hline
\end{tabular}

- PFIC-4 is not the result of a primary transport defect, but rather of an inborn error of bile salt synthesis, particularly 3beta-hydroxysteroid dehydrogenase deficiency (34). Failure to produce bile salts normally opens pathways that lead to the formation of hepatotoxic bile salts. These, in turn, produce cholestasis by inhibiting canalicular ATP-dependent bile acid transporters (41).

In cystic fibrosis, mutation of the CFTR gene impedes ductal secretion of chloride and water. The resultant mucous obstruction of intrahepatic ducts causes focal areas of biliary fibrosis and eventually cirrhosis (44).

\section{Acquired cholestatic syndromes}

In cholestatic illnesses, most changes in transporter expression in hepatocytes and cholangiocytes are actually adaptive responses that limit the accumulation of potentially toxic compounds in the liver $(31,45)$. Generally, alterations in the expression of canalicular transporters are primary events, because they are involved in the rate-limiting step for bile secretion. Compensatory changes occur in the basolateral transport systems. Despite the downregulation of uptake processes, the overall basolateral input still exceeds canalicular output in cholestasis; therefore, intracellular levels of bile salts increase (46). In some instances, alternative routes for bile salt processing are promoted. As summarized in Table 2 , the primary and secondary transporter changes can be grouped into the following four categories.
Basolateral membrane transport protein changes: Many of the changes that occur in this domain are reactive in nature and help to protect the hepatocyte from the effects of potentially toxic compounds:

- $\mathrm{Na}^{+} / \mathrm{K}^{+}$-ATPase (the sodium pump) is not a primary target in acquired cholestatic injury $(31,45)$. Its expression is preserved, or even increased, which helps promote liver cell survival.

- NTCP activity is decreased in animal models of cholestasis $(46,47)$ and in patients with estrogeninduced cholestasis (48). Although this reduction in hepatic uptake of bile salts might appear to exacerbate the impairment of bile formation, it also lessens any tendency for these potentially toxic bile salts to accumulate within the liver.

- OATP1 activity is upregulated in conditions such as primary sclerosing cholangitis, perhaps attempting to augment the excretion of noxious compounds (31). Nonetheless, OATP is suppressed in some animal models of cholestasis $(45,49)$.

- MRP1 and MRP3. These inducible transporters are strikingly increased in cholestasis, even when due to hereditary MRP2 deficiency (50). They help remove bilirubin conjugates and sulphated bile salts from the hepatocyte.

Canalicular membrane transport protein changes: The activities of some export pumps decrease, whereas others increase in apparent compensation. 
- MDR1 (exporter of xenobiotics and lipophilic toxins) increases in activity in cholestasis, likely as a compensatory response (31). MDR1 is also present on the luminal surface of cholangiocytes, where it may play a protective role (51).

- MDR3 (the phospholipid export pump) also increases in cholestasis.

- BSEP is relatively preserved in cholestasis. Its activity initially decreases but then partially recovers, thus tending to ameliorate bile salt retention in hepatocytes $(45,52)$.

- MRP2 (the conjugate export pump) decreases in patients with primary biliary cirrhosis (PBC) and in animal models of obstructive cholestasis. This accounts for the impaired biliary excretion of amphiphilic anionic conjugates in these disorders (45). Although the activity of this bilirubin export pump appears to be maintained in the initial phases of inflammatory cholestasis, it is later downregulated, which might lead to perpetuation of jaundice $(53,54)$.

- $\mathrm{Cl}^{-} / \mathrm{HCO}_{3}{ }^{-}$exchanger (AE2) expression is reduced in the bile canaliculus of patients with PBC (55). Its activity is also diminished in the salivary glands, likely as part of the generalized bicarbonate secretory failure in 'dry gland' syndromes, such as Sjögren's syndrome $(56,57)$. This alteration of the chloride/bicarbonate exchanger has not been found, however, in animal models of cholestasis.

Changes in cholangiocyte transport: Although cholangiocytes are the primary target for the cholestasis in the various 'vanishing bile duct syndromes', including PBC, limited information is available about their transport systems. In obstructive cholestasis, retained bile salts may induce the proliferation of cholangiocytes (58). Meanwhile, the receptors for secretin (the hormone that stimulates ductal bicarbonate secretion) are upregulated (59).

With ductal proliferation, increased expression and activity of the ileal sodium-dependent bile salt transporter should tend to enhance the return of any bile salts (which are excreted by residual BSEP activity) into the systemic circulation. This 'cholehepatic shunt', however, would be interrupted by downregulation of NTCP; the resultant decrease in the extraction of bile salts from the portal blood would enhance their elimination in the urine. The net effect of cholestasis is, therefore, to increase the urinary excretion of bile salts.

Morphological effects of cholestasis: Cholestasis disrupts the structural and functional integrity of tight junctions, causing a loss of the seal that normally prevents the regurgitation of bile into the plasma. These 'leaky' junctions allow an increase in paracellular permeability (60). This results in a loss of the osmotic gradient that normally drives water (and accompanying solutes) into the canalicular lumen. Moreover, cholestasis also disrupts the microtubules and actin filaments within the cytoskeleton that surrounds the canaliculus (3). This results in a loss of apical microvilli and diminished contractility of the canaliculus. The loss of tone leads to canalicular distension and the accumulation of bile plugs in the lumen.

\section{INTERPRETATION OF THE CASE}

The phenotypic features of the child described in the 'Case Presentation' - early onset of cholestasis, high serum rGT, and bile duct injury with portal inflammation that progressed to cirrhosis and liver failure - were characteristic of PFIC-3. The defect, a mutation of the MDR3 gene, resulted in failure to secrete the phospholipid lecithin into bile. Therefore, the secreted bile salts, rather than being bound up in mixed micelles, were free to cause canalicular and ductular damage. Ursodeoxycholic acid may help some patients with PFIC-3, particularly those with residual MDR3 function (61). This agent acts by reducing the hydrophobicity of bile salts - less detergent action means less damage. It also produces a marked choleresis. Although ursodeoxycholic acid generally improves the biochemical markers in several cholestatic disorders, benefit in terms of clinical outcome and survival remains unproven except for PBC.

The child's mother must have had a heterozygous, nonsense mutation of her MDR3 gene (62). The low phospholipid content in her bile predisposed her to the development of gallstones (38-41). The transient rise in female sex hormones (especially estrogens) during pregnancy would have further impaired MDR3, resulting in cholestasis of pregnancy (39). Estrogen also reduces sodium-dependent bile salt uptake (by markedly lowering NTCP) and bile salt transport $(48,52)$. The expression of BSEP, though reduced, is relatively preserved compared with other transport systems $(52,63)$. These effects of estrogen emphasize that inherited mutations in canalicular transporters can underlie a person's susceptibility to cholestatic injury.

Liver transplantation should 'cure' the transport defect and the disease. Would the heterozygous mother be an appropriate live donor?

\section{SUMMARY}

The hepatocyte is a polarized epithelial cell with two distinctive domains: basolateral (sinusoidal) and canalicular (apical). Transport proteins located in the basolateral and canalicular membranes have distinctive roles in mediating the translocation of organic compounds and small solutes across the hepatocyte into the canalicular lumen. The key process driving bile formation is the transport of bile salts from portal blood, across the basolateral (sinusoidal) surface of the hepatocyte and into the canalicular lumen to form bile. The basolateral transport systems take up potentially toxic compounds but are not directly dependent on ATP for their function. The sodium pump $\left(\mathrm{Na}^{+} / \mathrm{K}^{+}\right.$-ATPase $)$establishes the ion gradient across the cell membrane to facili- 
tate the sodium-dependent uptake of bile salts by NTCP. OATP takes up unconjugated bile salts and organic anions, independent of sodium.

Canalicular transport, the rate-limiting step in bile formation, acquires energy from the hydrolysis of ATP. These 'export' pumps belong to the $\mathrm{ABC}$ superfamily. Pgps consist of export pumps for phospholipids (MRP3 or MDR3) and bile salts (BSEP), as well as an aminophospholipid translocase (FIC1). Another canalicular ATP-dependent transporter, MRP2, excretes a broad range of organic anions, mostly conjugates with glucuronide (eg, bilirubin), GSH and sulphates.

Genetic defects in these canalicular transporters are responsible for several types of PFIC. PFIC-1 results from a mutation of the FIC1 gene. It also exhibits phenotypic heterogeneity: less severe disease occurs if the onset arises later in childhood, whereas mild expressions of nonprogressive liver disease can appear in the form of BRIC and intrahepatic cholestasis of pregnancy. PFIC-2 represents a failure to express BSEP, resulting in severe cholestasis. PFIC-3 results from a mutation of the MDR3 gene, causing a defect in expression of the phospholipid export pump, which in turn results in cholestasis and cholesterol cholelithiasis. This

\section{REFERENCES}

1. Shaffer EA, Barkun ANG. The biliary system. In: Thomson ABR, Shaffer EA, eds. First Principles of Gastroenterology, 4th edn. Milton: MacLean Communications, 2000:473-95.

2. Ujházy P, Kipp H, Misra S, Wakabayashi Y, Arias IM. The biology of the bile canaliculus. In: Arias IM, Boyer JL, Chisari FV, Fausto N, Schachter D, Shafritz DA, eds. The Liver: Biology, and Pathobiology, 4th edn. Philadelphia: Lippincott, Williams \& Williams, 2001:361-70.

3. Phillips MJ, Poucell S, Oda M. Mechanisms of cholestasis. Lab Invest 1986;54:593-608.

4. Bear CE, Shaffer EA. Hepatocellular water and electrolyte secretion. Can J Physiol Pharmacol 1988;66:1253-60.

5. Wheeler HO. Secretion of bile acids by the liver and their role in the formation of hepatic bile. Arch Intern Med 1972;130:533-41.

6. Ballatori N, Truong AT. Relation between biliary glutathione excretion and bile acid-independent bile flow. Am J Physiol 1989;256:G22-30.

7. Erlinger S. New insights into the mechanisms of hepatic transport and bile secretion. J Gastroenterol Hepatol 1996;11:575-9.

8. Boyer JL. Bile duct epithelium: frontiers in transport physiology. Am J Physiol 1996;270:G1-5.

9. Shaffer EA. Hepatobiliary system: structure and function. In: Walker WA, Durie PR, Hamilton JR, Walker-Smith JA, Watkins JB, eds. Pediatric Gastrointestinal Disease: Pathophysiology, Diagnosis and Management. Philadelphia: BC Decker, 1991:319-34.

10. Hagenbuch B, Meier PJ. Sinusoidal (basolateral) bile salt uptake systems of hepatocytes. Semin Liver Dis 1996;16:129-36.

11. Kullak-Ublick GA, Hagenbuch B, Stieger B, et al. Molecular and functional characterization of an organic anion transporting polypeptide cloned from human liver. Gastroenterology 1995;109:1274-82.

12. Kullak-Ublick GA. Regulation of organic anion and drug transporters of the sinusoidal membrane. J Hepatol 1999;31:563-73.

13. Kullak-Ublick GA, Stieger B, Hagenbuch B, Meier P. Hepatic transport of bile salts. Semin Liver Dis 2000;20:273-92.

14. Bahar RJ, Stolz A. Bile acid transport. Gastroenterol Clin North Am 1999;28:27-58.

15. Higgins CF. ABC transporters: from microorganisms to man. Annu Rev Cell Biol 1992;8:67-113.

16. Kipp H, Arias IM. Intracellular trafficking and regulation of canalicular ATP-binding cassette transporters. Semin Liver Dis 2000;20:339-51. deficiency of MDR3 exhibits a wide spectrum of phenotypic expression. Children with missense mutations express some MDR3. In these children, the disease develops later in life, is less severe and may respond to ursodeoxycholic acid. Heterozygotes may only exhibit problems when other factors (eg, estrogens) dramatically decrease the phospholipid transporter function and induce intrahepatic cholestasis. In acquired cholestasis, several bile salt and other transporters respond as if they were attempting to diminish the retention of bile salts and other potential toxins in the liver. The future may provide not only a better understanding of the basis for cholestasis but also perhaps therapeutic interventions to modify the expression of these hepatobiliary transporters.

Understanding these hepatic transport systems provides a vastly improved approach to the genetic basis of both pediatric and adult cholestatic syndromes, which are just now beginning to make sense. These mutations are on the verge of being uncovered by genetic testing, and the pharmacological manipulation of hepatobiliary transporters, upregulating key exporters and enhancing the compensatory adaptations that occur with acquired cholestasis, may soon be possible. For now, we are just learning the ABCs.

17. Hooiveld GJEJ, van Montfoort JE, Meijer DKF, Muller M. Function and regulation of ATP-cassette transport proteins involved in hepatobiliary transport. Eur J Pharm Sci 2001;12:525-43.

18. Weinman SA, Graf J, Boyer JL. Voltage-driven, taurocholatedependent secretion in isolated hepatocyte couplets. Am J Physiol 1989;256:G826-32.

19. Kast C, Stieger B, Winterhalter KH, Meier PJ. Hepatocellular transport of bile acids. Evidence for distinct subcellular localizations of electrogenic and ATP-dependent taurocholate transport in rat hepatocytes. J Biol Chem 1994;269:5179-86.

20. Silverman JA, Schrenk D. Hepatic canalicular membrane 4: Expression of the multidrug resistance genes in the liver. FASEB J 1997;11:308-13.

21. Oude Elferink RPJ, Tytgat GNJ, Groen AK. Hepatic canalicular membrane 1: The role of mdr2 P-glycoprotein in hepatobiliary lipid transport. FASEB J 1997;11:19-28.

22. De Vree JML, Jacquemin E, Sturm E, et al. Mutations in the MDR3 gene cause progressive familial intrahepatic cholestasis. Proc Natl Acad Sci USA 1998;95:282-7.

23. Strautnieks SS, Kagalwalla AF, Tanner MS, et al. Identification of a locus for progressive familial intrahepatic cholestasis PFIC2 on chromosome 2q24. Am J Hum Genet 1997;61:630-3.

24. Thompson RJ, Strautnieks SS. Genetic defects of canalicular transport. In: Arias IM, Boyer JL, Chisari FV, Fausto N, Schachter D, Shafritz DA, eds. The Liver: Biology, and Pathobiology, 4th edn. Philadelphia: Lippincott, Williams \& Williams, 2001:383-8.

25. Borst P, Evers R, Kool M, Wijnholds J. The multidrug resistance protein family. Biochim Biophys Acta 1999;1461:347-57.

26. Keppler D, Konig J, Nies AT. Conjugate export pumps of the multidrug resistance protein (MRP) family in liver. In: Arias IM, Boyer JL, Chisari FV, Fausto N, Schachter D, Shafritz DA, eds. The Liver: Biology, and Pathobiology, 4th edn. Philadelphia: Lippincott, Williams \& Williams, 2001:373-83.

27. Kartenbeck J, Leuschner U, Mayer R, Keppler D. Absence of the canalicular isoform of the MRP gene-encoded conjugate export pump from the hepatocytes in Dubin-Johnson syndrome. Hepatology 1996;23:1061-6.

28. Bruck R, Benedetti A, Strazzabosco M, Boyer JL. Intracellular alkalinization stimulates bile flow and vesicular-mediated exocytosis in IPRL. Am J Physiol 1993;265:G347-53.

29. Strazzabosco M. Transport systems in cholangiocytes: their role in bile formation and cholestasis. Yale J Biol Med 1997;70:427-34. 
30. Alpini G, Glaser SS, Rodgers R, et al. Functional expression of the apical $\mathrm{Na}^{+}$-dependent bile acid transporter in large but not small rat cholangiocytes. Gastroenterology 1997;113:1734-40.

31. Trauner M, Meier PJ, Boyer JL. Molecular regulation of hepatocellular transport systems in cholestasis. J Hepatol 1999;31:165-78.

32. Jacquemin E, Hadchouel M. Genetic basis of progressive familial intrahepatic cholestasis. J Hepatol 1999;31:377-81.

33. Jansen PLM, Müller M. The molecular genetics of familial intrahepatic cholestasis. Gut 2000;47:1-5.

34. Bezerra JA, Balistreri WF. Cholestatic syndromes of infancy and childhood. Semin Gastrointest Dis 2001;12:54-65.

35. Bull LN, van Eijk MJT, Pawlikowska L, et al. A gene encoding a P-type ATPase mutated in two forms of hereditary cholestasis. Nat Genet 1998;18:219-24.

36. Tygstrup N, Steig BA, Juijn JA, Bull LN, Houwen RH. Recurrent familial intrahepatic cholestasis in the Faeroe Islands. Phenotypic heterogeneity but genetic homogeneity. Hepatology 1999;29:506-8.

37. Jansen PLM, Strautnieks SS, Jacquemin E, et al. Hepatocanalicular bile salt export pump deficiency in patients with progressive familial intrahepatic cholestasis. Gastroenterology 1999;117:1370-9.

38. Jacquemin E, de Vree JML, Cresteil D, et al. The wide spectrum of multidrug resistance 3 deficiency: from neonatal cholestasis to cirrhosis of adulthood. Gastroenterology 2001;120:1448-58.

39. Rosmorduc O, Hermelin B, Poupon R. MDR3 gene defect in adults with symptomatic intrahepatic and gallbladder cholesterol cholelithiasis. Gastroenterology 2001;120:1459-67.

40. Fracchia M, Pellegrino S, Secreto P, et al. Biliary lipid composition in cholesterol microlithiasis. Gut 2001;48:702-6.

41. Kapadia CR. Patients with biliary microlithiasis: are they a separate breed? Gastroenterology 2001;121:1014-6.

42. Ortiz D, Arias IM. MDR3 mutations: a glimpse into Pandora's box and the future of canalicular pathophysiology. Gastroenterology 2001;120:1549-52.

43. Stieger B, Zhang J, O’Neill B, Sjövall J, Meier PJ. Differential interaction of bile acids from patients with inborn errors of bile acid synthesis with hepatocellular bile acid transporters. Eur J Biochem 1997;244:39-44.

44. Feranchak AP, Sokol RJ. Cholangiocyte biology and cystic fibrosis liver disease. Semin Liver Dis 2001;21:471-88.

45. Lee J, Boyer JL. Molecular alterations in hepatocyte transport mechanisms in acquired cholestatic liver disorders. Semin Liver Dis 2000;20:373-84.

46. Bolder U, Ton-Nu H-T, Schteingart CD, Frick E, Hofmann AF. Hepatocyte transport of bile acids and organic anions in endotoxemic rats: impaired uptake and secretion. Gastroenterology 1997;112:214-25

47. Gartung C, Ananthanarayanan M, Rahman MA, et al. Downregulation of expression and function of the rat liver $\mathrm{Na}+/$ bile acid cotransporter in extrahepatic cholestasis. Gastroenterology 1996;110:199-209.
48. Simon FR, Fortune J, Iwahashi M, Gartung C, Wolkoff A, Sutherland E. Ethinyl estradiol cholestasis involves alterations in expression of liver sinusoidal transporters. Am J Physiol 1996;271:G1043-52.

49. Trauner M, Boyer JL. Cholestatic syndromes. Curr Opin Gastroenterol 2000;16:239-50.

50. Ogawa K, Suzuki H, Hirohashi T, et al. Characterization of inducible nature of MRP3 in rat liver. Am J Physiol 2000;278:G438-46.

51. Gigliozzi A, Fraioli F, Sundaram P, et al. Molecular identification and functional characterization of Mdr1a in rat cholangiocytes. Gastroenterology 2000;119:1113-22.

52. Lee JM, Trauner M, Soroka CJ, Stieger B, Meier PJ, Boyer JL. Expression of the bile salt export pump is maintained after chronic cholestasis in the rat. Gastroenterology 2000;118:163-72.

53. Trauner M, Arrese M, Soroka CJ, et al. The rat canalicular conjugate export pump (Mrp2) is down-regulated in intrahepatic and obstructive cholestasis. Gastroenterology 1997;113:255-64.

54. Kubitz R, Wettstein M, Warskulat U, Häussinger D. Regulation of the multidrug resistance protein 2 in the rat liver by lipopolysaccharide and dexamethasone. Gastroenterology 1999;116:401-10.

55. Medina JF, Martínez-Ansó E, Vázquez JJ, Prieto J. Decreased anion exchanger 2 immunoreactivity in the liver of patients with primary biliary cirrhosis. Hepatology 1997;25:12-7.

56. Epstein O, Thomas HC, Sherlock S. Primary biliary cirrhosis is a dry gland syndrome with features of chronic graft-versus-host disease. Lancet 1980;i:1166-8.

57. Vázquez JJ, Vázquez M, Idoate MA, et al. Anion exchanger immunoreactivity in human salivary glands in health and Sjögren's syndrome. Am J Pathol 1995;146:1422-32.

58. Alpini G, Glaser SS, Ueno Y, et al. Bile acid feeding induces cholangiocyte proliferation and secretion: evidence for bile acidregulated ductal secretion. Gastroenterology 1999;116:179-86.

59. Alpini G, Ulrich CD II, Phillips JO, Pham LD, Miller LJ, LaRusso NF. Upregulation of secretin receptor gene expression in rat cholangiocytes after bile duct ligation. Am J Physiol 1994;266:G922-8.

60. Anderson JM. Leaky junctions and cholestasis: a tight correlation. Gastroenterology 1996;110:1662-5.

61. Jacquemin E, Hermans D, Myara A, et al. Ursodeoxycholic acid therapy in pediatric patients with progressive familial intrahepatic cholestasis. Hepatology 1997;25:519-23.

62. Jacquemin E, Cresteil D, Manouvrier S, Boute O, Hadchouel M. Heterozygous non-sense mutation of the MDR3 gene in familial intrahepatic cholestasis of pregnancy. Lancet 1999;353:210-1. (Lett)

63. Stieger B, Fattinger K, Madon J, Kullak-Ublick GA, Meier PJ. Drug- and estrogen-induced cholestasis through inhibition of the hepatocellular bile salt export pump (Bsep) of rat liver. Gastroenterology 2000;118:422-30. 


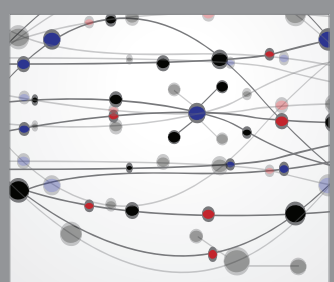

The Scientific World Journal
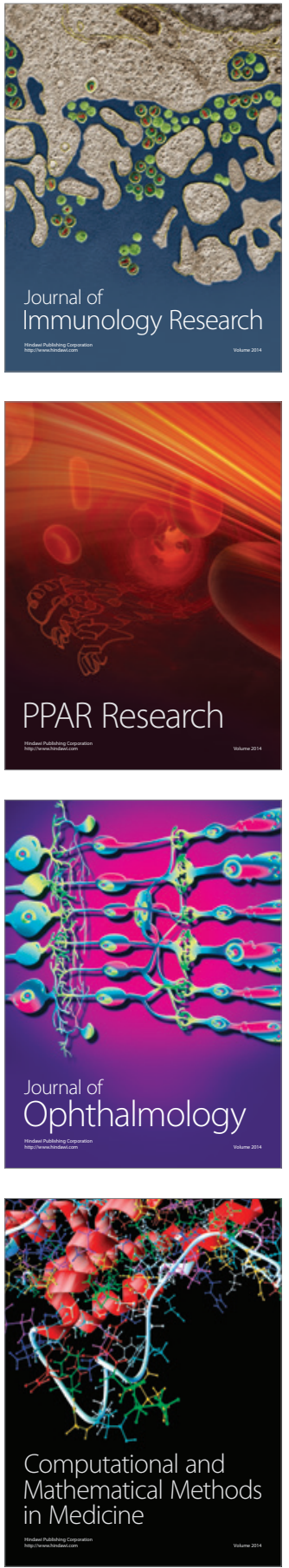

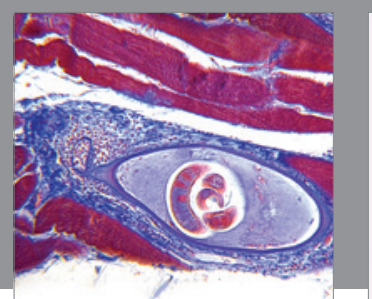

Gastroenterology Research and Practice

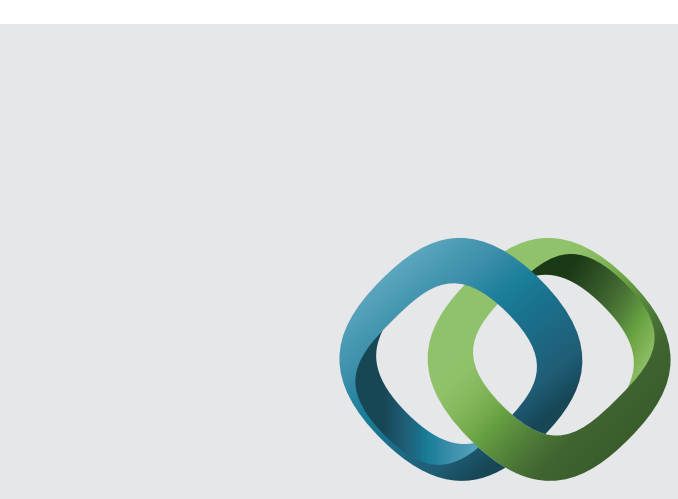

\section{Hindawi}

Submit your manuscripts at

http://www.hindawi.com
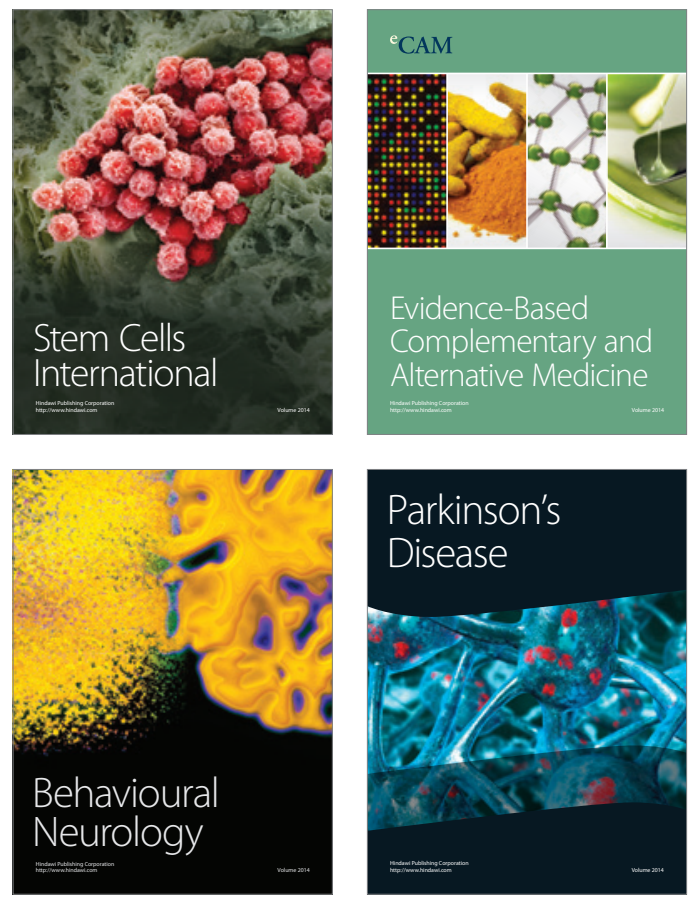
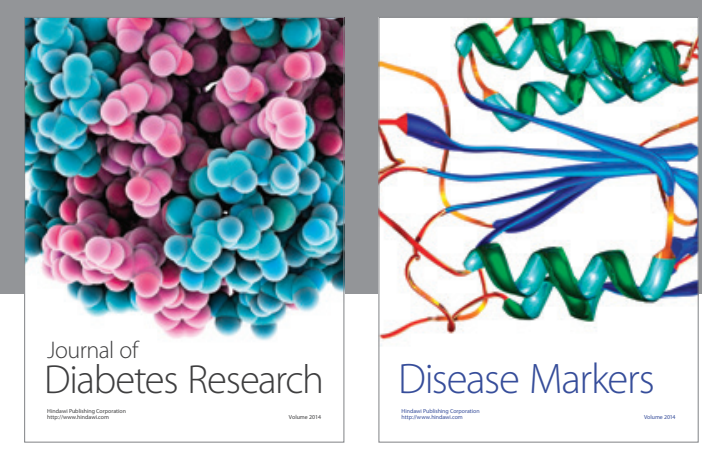

Disease Markers
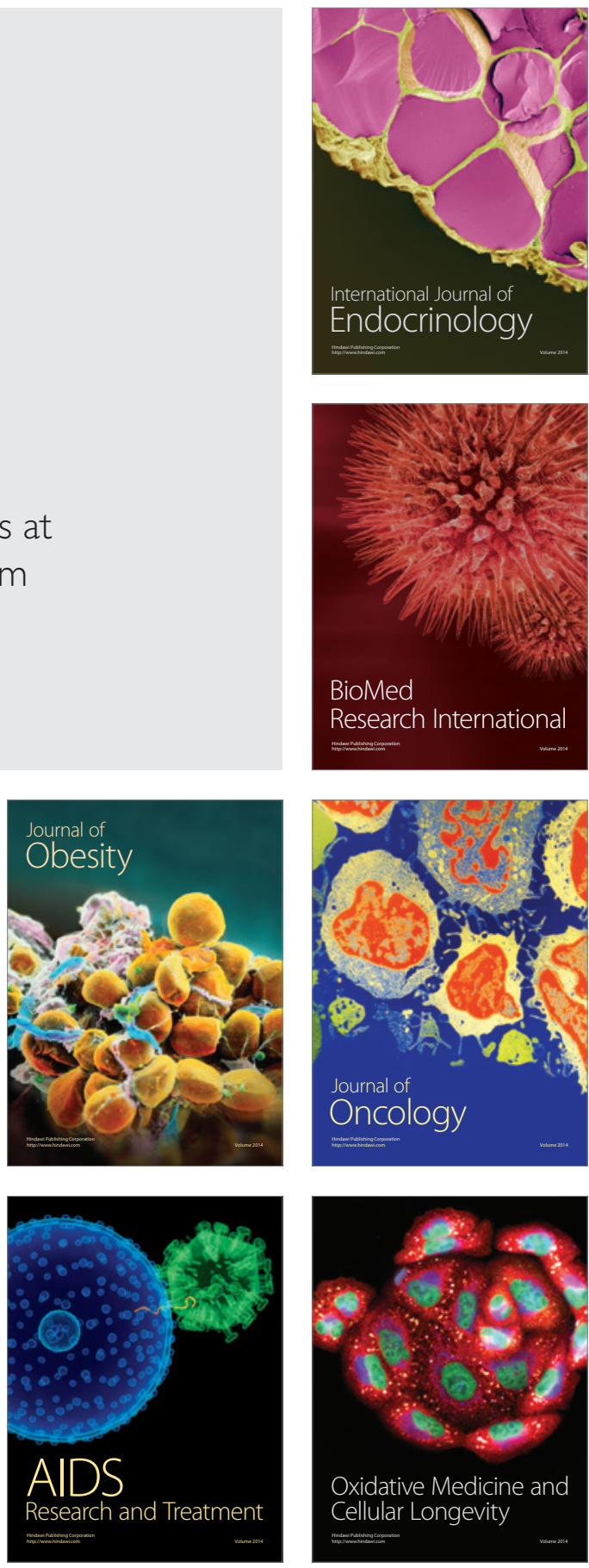